\title{
The influence of alkaline activator concentration on the apparent activation energy of alkali- activated materials
}

\author{
Dariusz Mierzwiński ${ }^{1, *}$, Janusz Walter ${ }^{1}$, and Piotr Olkiewicz ${ }^{2}$ \\ ${ }^{1}$ Cracow University of Technology, Institute of Materials Engineering, Faculty of Materials \\ Engineering and Physics, Warszawska 24, 31-155 Kraków, Poland \\ ${ }^{2}$ SENVI Sustainability Consultants, Płocka 15, 01-231 Warszawa, Poland
}

\begin{abstract}
The aim of this article is to analyse the changes of apparent activation energy $\left(E_{a}\right)$ of alkali-activated materials (AAM) at temperatures up to $100^{\circ} \mathrm{C}$. Apparent activation energy $\left(E_{a}\right)$ refers to the minimum amount of energy is required for the occurrence of reaction. The existing AAM research is based on assumptions about Portland cement (OPC). A number of studies have been conducted on the development of concrete strength depending on, inter alia, the duration of seasoning and the liquid to solid ratio (L/S). Based on the apparent activation energy and taking into account the effect of time and temperature at the same time, the physical and mechanical properties of OPC can also be predicted. The influence of the activator on the solidification process should also be taken into account for alkali-activated materials. This article shows the effect of changes in the concentration of the alkaline solution used in the AAM process on activation energy. The synthesized AAM material uses a solution based on water glass, sodium hydroxide, sand and volatile ash from the 'Skawina' coal-fired power plant (located in Skawina, Lesser Poland). The chemical composition of the material used is classified as class $\mathrm{F}$ ash. The concentration of the alkaline solution was $8 \mathrm{M}, 10 \mathrm{M}$, $12 \mathrm{M}$ and $14 \mathrm{M}$. The described research method was based on the use of thermistors with a negative temperature factor. It enabled prediction of the physical and mechanical properties of the materials tested. The results clearly indicate that this method can be used to determine the activation energy of the AAM. However, when determining apparent activation energy $\left(\mathrm{E}_{\mathrm{a}}\right)$, the time and activation temperature of the binding processes of these types of materials should be taken into consideration.
\end{abstract}

\section{Introduction}

Carbon fly ash (CFA) is an unavoidable by-product of thermal energy production from coal combustion [1-5]. Of the total amount of ash produced, CFA constitutes $85-95 \%$ wt. and consists of fine particles of fly ash retained from the flue gas [6]. Although much effort has recently been devoted to green energy, such as solar and wind energy, burning coal

* Corresponding author: dariusz.mierzwinski@pk.edu.pl 
remains the main method of supplying electricity worldwide. Currently, CFA is either removed to ash / lagoon / landfill ponds or recycled in many other industries for a variety of applications [7]. CFA has beneficial physico-chemical properties, such as low bulk density, essential nutrients for plants and high-water retention, which means that it can enrich oil. Many publications have shown that CFA can replace some lime in cement production [8-10].

Alkali-activated materials (AAM) are produced by mixing selected precursors such as fly ash and milled granular blast furnace slag (GGBS) with an alkaline source in solid or solution form. What is considered industrial waste or by-products can be used to produce cement materials without the high-temperature calcination process used in cement production. This reduces $\mathrm{CO}_{2}$ emissions and the extraction of natural resources. The microstructure of alkali activated fly ash (AAFA or 'geopolymer' used in various sources [11]) is dense, and due to the low calcium content, it is less susceptible to the descaling reaction. However, AAFA composites have relatively low compressive strength, especially at an early age, due to the incomplete dissolution of fly ash at room temperature [12].

Plain Portland cement (OPC) is the most widely used cement material in civil engineering. The OPC paste hydration reaction is accompanied by the release of a huge amount of heat from hydration, which increases the internal temperature of the concrete mass structure. After limiting thermal deformation, it is easy to cause the concrete surface to crack and thus seriously affect the durability and safety of the structure. Therefore, attenuation of the temperature rise inside the concrete structure is one of the ways to prevent cracking in concrete structures $[13,14]$. The right choice of the type of cement material is considered a simple and effective method of controlling the formation of cracks. Cement material with low heat evolution should be widely used in mass concrete $[15,16]$.

To predict the preservation of concrete strength, many studies have been performed based on cement hydration phenomena [17]. In addition, it is necessary to assess the mechanical properties of concrete, such as compressive strength, tensile strength, tensile modulus, creep, shrinkage, etc. Of the mechanical properties used in design, compressive strength is the most important because other properties can be estimated from it. There are various models of strength development, including maturity models based on the concept of age. It is widely used to assess concrete compressive strength assuming a linear relationship with temperature or a non-linear relationship with the chemical reaction rate of cement. Due to the range of curing temperatures and the accuracy of the forecast result, an equivalent age model is widely used to interpret strength development, which takes into account the cement chemical reaction rate. In the chemical reaction rate model, it is believed that the apparent activation energy $\left(E_{a}\right)$ is a key parameter with the cure temperature in the hydration reaction $[18-20] . \mathrm{E}_{\mathrm{a}}$ is indirectly proportional to the compressive strength, as suggested in ASTM C 1074-11 [21].

This paper describes the possibility of using NTC thermistors to determine thermal phenomena occurring during binding in alkali-activated materials.

\section{Materials and methods}

\subsection{Materials}

For the manufacture of alkali-activated materials, fly ash from the CHP plant in Skawina (Poland) was used. The chemical composition of this fly ash is typical of class F [22]. The amount of reactive silica in the investigated material is acceptable (around 36\%). It has good physical parameters - the content of particles under the size of $45 \mu \mathrm{m}$ is around $88 \%$ 
$[1,23]$. The fly ash contains a lot of spherical particles and has good workability [2]. The mineralogical structure investigations show the presence of a large amount of amorphous phase [2]. The features of fly ash make it an ideal raw material for use in the geopolymerisation process.

\subsection{Sample preparation}

Fly ash and a sand mixture $(1: 1)$ were used to produce alkaline activated materials. $\mathrm{NaOH}$ (Sigma-Aldrich) solutions of $8 \mathrm{M}, 10 \mathrm{M}, 12 \mathrm{M}, 14 \mathrm{M}$ molar concentrations with aqueous sodium silicate (R-145, 2.5 molar ratio, density $1.45 \mathrm{~g} \mathrm{~cm}^{-3}$ ) were used for the activation process. The liquid to solid ratio was 0.4 . The fly ash, sand and alkaline solution were mixed for $15 \mathrm{~min}$ in a low-speed mixing machine to form a homogeneous paste. The prepared mixtures $\left(\mathrm{FA}_{8 \mathrm{M}}-\mathrm{FA}_{14 \mathrm{M}}\right)$ were transferred into a cylindrical form of the same volume, in accordance with EN 13791. The material prepared in this way with a slightly liquid consistency was immediately used to fill the prepared cylindrical forms. In the next step, a vibrator was used to remove air bubbles from the mould filled with material. The prepared thermistor was placed in the filled moulds.

Standard thermistors with a negative temperature coefficient (NTCLE100E3, Vishay) were used to build the probe system. The thermistors consisted of an integrated circuit with two solid, galvanised copper wires. The tests used thermistors with a resistance of $R_{\text {ref }}=R 25=$ $10,000 \Omega$.

The thermistor calibration was performed with distilled water of known temperature. Due to the alkaline $\mathrm{pH}$ of the geopolymer mass, a new thermistor was used for each sample. Changes in the resistance value were recorded using the ATLAS 0531 impedance analyser. The measurements were conducted within 24 hours in a $75^{\circ} \mathrm{C}$ oven. The samples were then transferred to ambient temperature for 48 hours, followed by another measurement cycle. The measurements were performed for 24 hours in a $75^{\circ} \mathrm{C}$ oven (using the test material as a reference sample). On the basis of current-voltage data obtained during measurements, thermal effects were calculated using the Steinhart-Hart law. The Steinhart-Hart coefficients are based on temperature resistance tables for given thermistors and functions (extended Steinhart-Hart polynomial), enabling the conversion of temperature to resistance and vice-versa [24].

The Steinhart-Hart calculation formula is sufficiently accurate with a deviation of $\pm 0.15^{\circ} \mathrm{C}$ in the temperature range $-50^{\circ} \mathrm{C}$ to $+150^{\circ} \mathrm{C}$. This accuracy meets the requirements for most analyses and technical applications. However, if higher accuracy is required, the operating range of the thermistor selected in this particular example should be narrowed to a range of $0^{\circ} \mathrm{C}$ to $+100^{\circ} \mathrm{C}$, which allows a level of accuracy higher than $\pm 0.01^{\circ} \mathrm{C}$ within this temperature range.

The sample with the dissolved geopolymer was then placed in a preheated oven and set at a stable temperature of $75^{\circ} \mathrm{C}$ for 24 hours to heat it and bring it to full polymerisation and cure. During the running time, voltage changes on the thermistor were recorded at uniform intervals, at a constant set current I = const through the connected galvanostatpotentiostat and through a connected computer.

\section{Apparent activation energy}

Maturity is a function that quantitatively represents the effect of both curing temperature and time on the development of concrete compressive strength and is expressed as an equation combining the curing function and the time function at a certain reference temperature. (1) 


$$
M=\int_{0}^{t} h(T) d t
$$

where $\mathrm{M}$ is maturity and $\mathrm{h}(\mathrm{T})$ is the maturity function. $\mathrm{T}$ denotes curing temperature over age of $\mathrm{t}$.

Cement reacts to water resulting in hydration and the degree of hydration is affected by the hydration rate at early age. The strength development of the concrete can be represented by the hydration rate because the strength development of concrete correlates with the hydration of the cement paste. The hydration rate is governed by the reaction rate constant of the point when the cement paste and water react $[25,26]$.

The degree of hydration of Portland cement can be derived by the weight ratio of reaction products. The weight ratio of reaction products can be determined by non-hydrated cement using an electron microscope or X-ray diffraction analysis [27-30].

The reaction rate constant is an indicator of the initial gradient for the degree of hydration. As the hydration rate quickens, the reaction rate constant increases whereas when the hydration rate slows down, the reaction rate constant decreases. Many factors influence the rate constant, some of which are correlated with each other. It is difficult to quantitatively predict the effect of temperature on the reaction rate constant because these factors influence the reaction rate constant simultaneously. However, the reaction rate constant is represented by the function of curing temperature if other conditions are identical. It is known that the reaction rate constant is influenced by the types of cement, the curing temperature, liquid to solids ratio (\%), admixture, and humidity conditions etc. [31-34].

Using the above assumptions, it was decided to determine the specific reaction points of the alkaline activation process in fly ash.

\section{Results}

Figures $1-4$ present the thermal effects recorded with the NTC thermistor system during the alkaline activation process as well as $48 \mathrm{~h}$ after curing (reference sample) for individual materials $\mathrm{FA}_{8 \mathrm{M}}$ (Fig. 1), $\mathrm{FA}_{10 \mathrm{M}}$ (Fig. 2), $\mathrm{FA}_{12 \mathrm{M}}$ (Fig. 3) and $\mathrm{FA}_{14 \mathrm{M}}$ (Fig. 4). Several characteristic effects can be determined for each material: the maximum value of the thermal effects, the time when thermal effect reaches the highest value and the end time of thermal effects. The highest value, $77.59^{\circ} \mathrm{C}$, for the thermal effects was recorded during the test of $\mathrm{FA}_{14 \mathrm{M}}$ (Fig. 4, Table 1). The $\mathrm{FA}_{8 \mathrm{M}}$ raw material was characterised by a lower value, $76.26^{\circ} \mathrm{C}$ (Fig. 1, Table 1). The time distribution of the thermal effects was negatively related to temperature; the higher the temperature, the shorter the time of both the maximum effects and their termination. Similarly, a subtraction performed between the temperature curve recorded for the alkaline activation process and for the corresponding formed geopolymer showed that raw material $\mathrm{FA}_{14 \mathrm{M}}$ is characterised by the most intense thermal effects with the shortest duration of around $9.5 \mathrm{~h}$.

Comparing the changes in the molar concentration of the alkaline solution in the samples tested, one can observe changing exothermic effects. It is believed that exothermic effects mainly result from the dissolution of solid fly ash components in a strongly alkaline aqueous solution and the disintegration of fly ash particles together with the formation of oligomeric compounds in the aqueous phase in combination with the formation of alumina / silica-hydroxy type. Polymerisation / condensation reactions can be attributed to a small share of heat evolution, which means that the process of network consolidation is a rather thermally stable state $[3,29,35]$. 


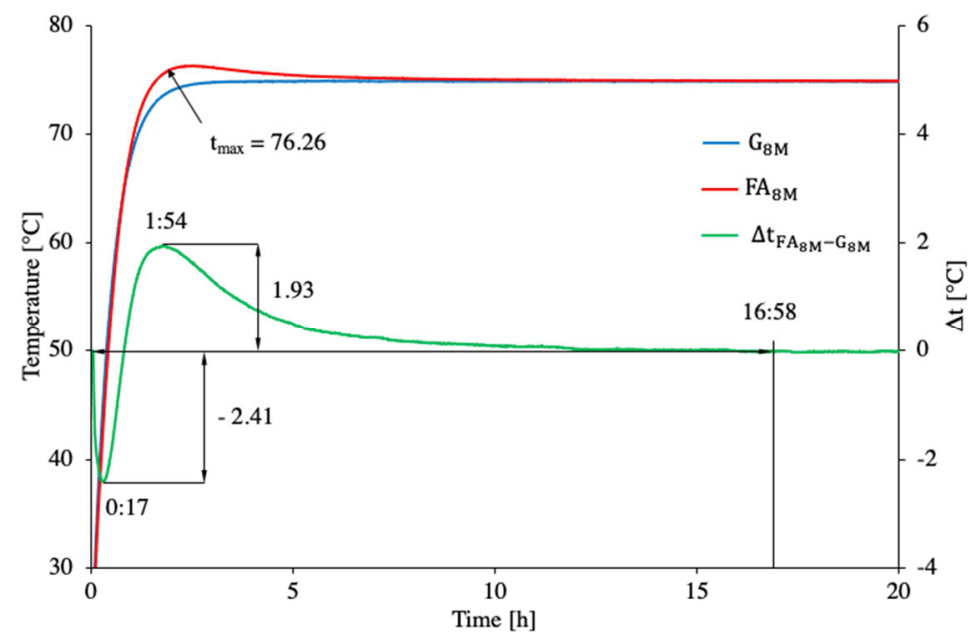

Fig. 1 Thermal effects recorded with the NTC thermistor system during the geopolymerisation process $\left(\mathrm{FA}_{8 \mathrm{M}}\right.$, red curve), $48 \mathrm{~h}$ after curing $\left(\mathrm{G}_{8 \mathrm{M}}\right.$, reference sample, blue curve), and the subtraction performed between temperature curves $\mathrm{FA}_{8 \mathrm{M}}$ and $\mathrm{G}_{8 \mathrm{M}}$ (green curve)

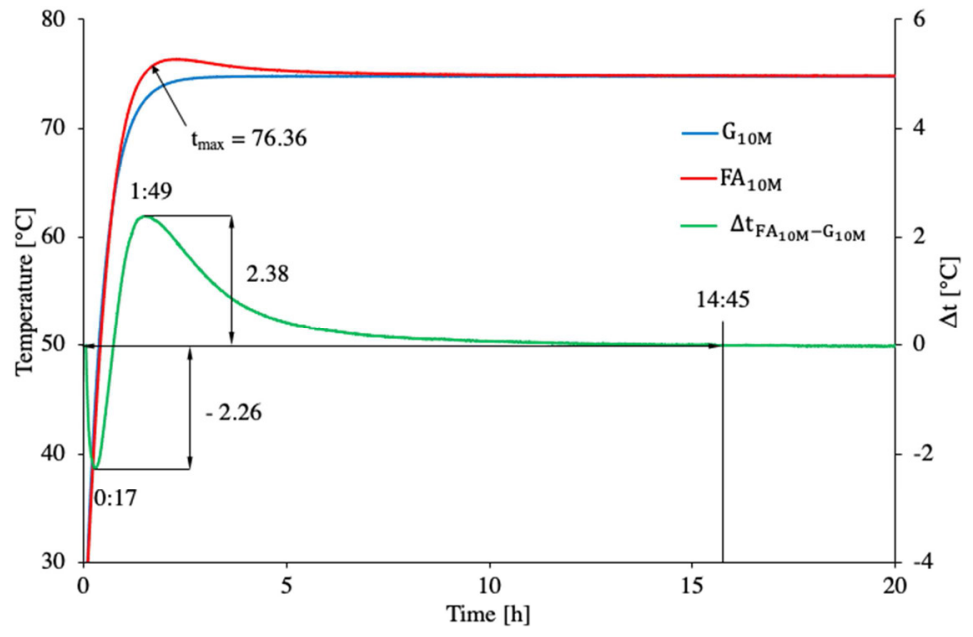

Fig. 2 Thermal effects recorded with the NTC thermistor system during the geopolymerisation process $\left(\mathrm{FA}_{10 \mathrm{M}}\right.$, red curve), $48 \mathrm{~h}$ after curing $\left(\mathrm{G}_{10 \mathrm{M}}\right.$, reference sample, blue curve), and the subtraction performed between temperature curves $\mathrm{FA}_{10 \mathrm{M}}$ and $\mathrm{G}_{10 \mathrm{M}}$ (green curve) 


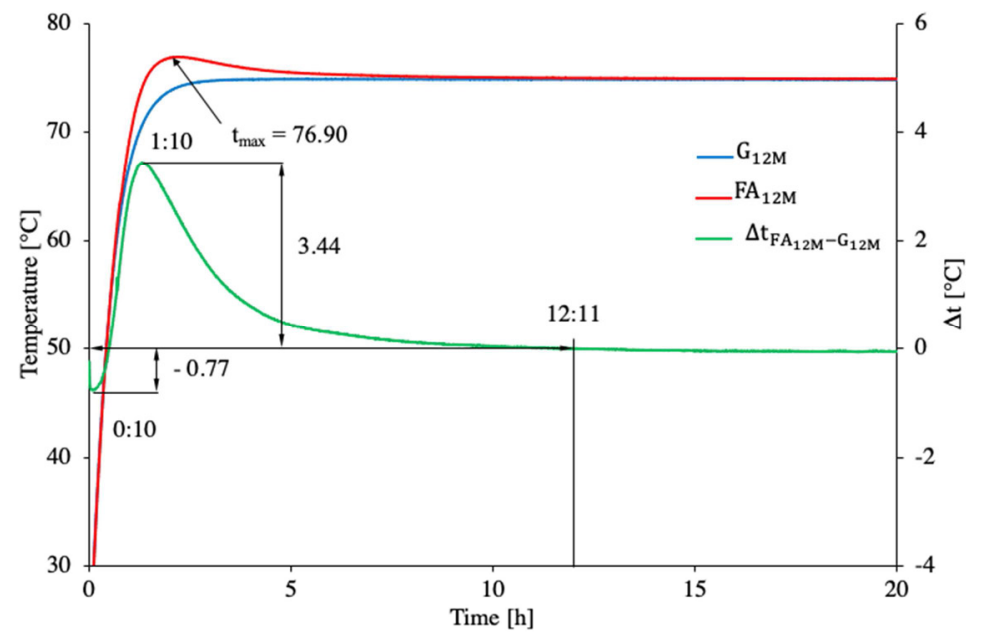

Fig. 3 Thermal effects recorded with the NTC thermistor system during the geopolymerisation process $\left(\mathrm{FA}_{12 \mathrm{M}}\right.$, red curve), $48 \mathrm{~h}$ after curing $\left(\mathrm{G}_{12 \mathrm{M}}\right.$, reference sample, blue curve), and the subtraction performed between temperature curves $\mathrm{FA}_{12 \mathrm{M}}$ and $\mathrm{G}_{12 \mathrm{M}}$ (green curve)

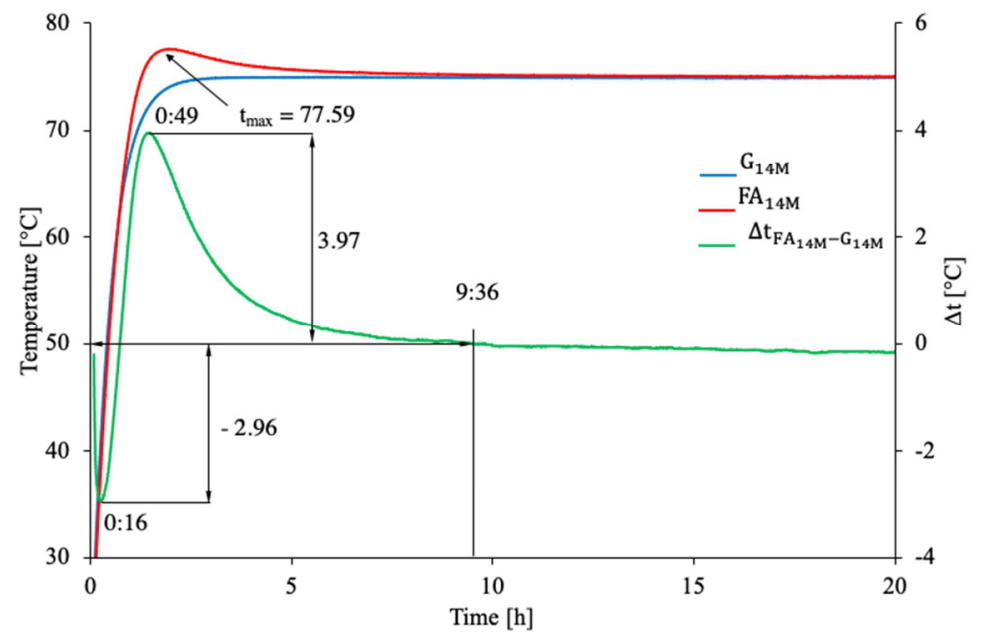

Fig. 4 Thermal effects recorded with the NTC thermistor system during the geopolymerisation process $\left(\mathrm{FA}_{14 \mathrm{M}}\right.$, red curve), $48 \mathrm{~h}$ after curing $\left(\mathrm{G}_{14 \mathrm{M}}\right.$, reference sample, blue curve), and the subtraction performed between temperature curves $\mathrm{FA}_{14 \mathrm{M}}$ and $\mathrm{G}_{14 \mathrm{M}}$ (green curve)

Table 1 Thermal effects recorded by the NTC thermistor system to changes in the molar concentration of alkaline solution in fly ash

\begin{tabular}{|l|r|r|r|r|}
\hline & FA8M & FA10M & FA12M & FA14M \\
\hline Max temp. $\left[{ }^{\circ} \mathrm{C}\right]$ & 76.26 & 76.36 & 76.90 & 77.59 \\
\hline The time of max. thermal effects [h] & $1: 54$ & $1: 49$ & $1: 10$ & $0: 49$ \\
\hline End-set time of thermal effects [h] & $16: 58$ & $14: 45$ & $12: 11$ & $9: 36$ \\
\hline $\begin{array}{l}\text { The temperature difference between maximum } \\
\text { temperatures process geopolymerisation a reference } \\
\text { sample }\left[{ }^{\circ} \mathrm{C}\right]\end{array}$ & 1.93 & 2.38 & 3.44 & 3.97 \\
\hline
\end{tabular}




\section{Conclusions}

Based on the results, the possibility of using the NTC thermistor probe system as a cheap method of analysing phenomena occurring during alkaline activation processes of materials was confirmed. The presented method together with other tests enable the determination of the influence of the molar concentration of the alkaline solution on the AAM hardening time. The NTC thermistor system made it possible to predict the selection of annealing temperature appropriate for a given process and the initial setting time at elevated temperatures.

\section{References}

1. Y. Luo, Y.-H. Wu, S.-H. Ma, S.-L. Zheng, P.K. Chu, J. Clean. Prod. 214, (2019)

2. Y. Shi, K.-X. Jiang, T.-A. Zhang, G.-Z. Lv, J. Clean. Prod. 243, 118470, (2020)

3. D. Valeev, I. Kunilova, A. Alpatov, A. Mikhailova, M. Goldberg, A. Kondratiev, J. Clean. Prod. 218, (2019)

4. Y. Xue, W. Yu, J. Mei, W. Jiang, X. Lv, J. Clean. Prod. 240, 118262, (2019)

5. J. Yang, J. Huang, Y. Su, X. He, H. Tan, W. Yang, B. Strnadel, J. Clean. Prod. 238, 117962, (2019)

6. Z. T. Yao, X.S. Ji, P.K. Sarker, J.H. Tang, L.Q. Ge, M.S. Xia, Y.Q. Xi, Earth-Sci. Rev. 141, (2015)

7. M. Ilic, C. Cheeseman, C. Sollars, J. Knight, Fuel 82 (3), (2003)

8. H. He, Z. Dong, J. Pang, G.-L. Wu, J. Zheng, X. Zhang, Sci. Total Environ. 630, (2018)

9. J. Leclercq-Dransart, S. Demuynck, G. Bidar, F. Douay, F. Grumiaux, B. Louvel, C. Pernin, A. Leprêtre, Appl. Soil Ecol. 138, (2019)

10. V. C. Pandey, P.C. Abhilash, N. Singh, J. Environ. Manage. 90 (10), (2009)

11. J. L. Provis, J.S.J. van Deventer. Alkali Activated Materials. 13, Springer Dordrecht Heidelberg New York London; (2014)

12. C. Chen, W. Gong, W. Lutze, I.L. Pegg, J. Zhai, J. Mater. Sci. 46, (2011)

13. J. H. Ha, Y.S. Jung, Y.G. Cho, Autom. Constr. 45, (2014)

14. Y. Bao, W.N. Meng, Y.Z. Chen, G.D. Chen, K.H. Khayat, Mater. Lett. 145, (2015)

15. B. Klemczak, M. Batog, M. Pilch, A. Zmij, Procedia Eng. 193, (2017)

16. M. H. Lee, B.S. Khil, H.D. Yun, Indian J. Eng. Mater. Sci. 21, (2014)

17. P. K. Mehta, P. Monteiro, Concrete: Microstructure, Properties, and Materials, Fourth Edition (2014)

18. P. Freiesleben, J. Pedersen, CEB Inf. Bull. 166, (1985)

19. X. Xiong, K.V. Breugel, Heron. J. 46, (2001)

20. A. K. Schindler, K.J. Folliard, ACI Mater. J. 102, (2005)

21. ASTM C1074-11 (2015)

22. K. Korniejenko, N.P. Halyag, and G. Mucsi, IOP Conf. Series: Mat. Sci. \& Eng. 706, 012006 (2019)

23. K. Korniejenko, G. Mucsi, N.P. Halyag, R. Szabó, D. Mierzwiński, P. Louda, KnE Engineering, 86, (2020) 
24. D. Mierzwiński, M. Łach, M. Hebda, J. Walter, M. Szechyńska-Hebda, J. Mikuła, J Therm Anal Calorim 138, (2019)

25. R. C. Tank, N.J. Carino, ACI Mater. J. 88, (1991)

26. M. N. Soutsos, S.J. Barnett, J.H. Bungey, S.G. Millard, ACI SP-228 1, (2005).

27. X. Y. Wang, Materials 10, (2017)

28. B. E. I. Abdelrazig, D.G. Bonner, Acta 145, (1989)

29. R. S. Lin, X.Y. Wang, H.S. Lee, H.K. Cho, Materials, 12, (2019)

30. Narmluk, M.T. Nawa, Cem. Concr. Res. 41, (2011)

31. P.K. Mehta, P. Monteiro, Concrete: Microstructure, Properties, and Materials, Fourth Edition (2014)

32. J. Beaudoin, J. Marchand, B. Tamtsia, R. Myers, Z. Liu, Cem. Based Mater. 8 (1998)

33. E. García Alcocel, P. Garcés, S. Chinchón, Cem. Concr. Res. 20, (2000)

34. G. del Cura, P. Garcés, Cem. Concr. Res. 29, (1999)

35. M. S. Muñiz-Villarreala, A. Manzano-Ramíreza, S. Sampieri-Bulbarelaa, J. R. GascaTiradoa, J. L. Reyes-Araizaa, J. C. Rubio-Ávalosa, J.J. Pérez-Buenob, L.M. Apatigac, A. Zaldivar-Cadenad, V. Amigó-Borrás, Mater Lett. 65 (6), (2011) 